\title{
Examination of CFTR Gene Mutations in Patient Groups with Borderline Sweat Test and Clinical Preliminary Diagnosis of Cystic Fibrosis by Next-Generation Sequencing Method in Şanlıurfa Province
}

\author{
Evren Gümüş (D)
}

Department of Medical Genetics, Harran University School of Medicine, Şanlıurfa, Turkey

Cite this article as: Gümüş E. Examination of CFTR Gene Mutations in Patient Groups with Borderline Sweat Test and Clinical Preliminary Diagnosis of Cystic Fibrosis by Next-Generation Sequencing Method in Şanlıurfa Province. JAREM 2019; 9(2): 86-90.

\begin{abstract}
Objective: Cystic fibrosis (CF) is the most common autosomal recessive mortal disease in the Caucasians. Its prevalence is $1 / 2500-3300$, and its carrier frequency is $1 / 20-25$. A mutation at the cystic fibrosis transmembrane conductance regulator (CFTR) gene, which is also known as chlorine permeable transmembrane channel, results in CF. There is a difference in the distribution of patients between patient groups and regions. This paper aimed to investigate the mutation dispersion in the state of Sanliurfa in patients who have borderline sweat test results or a clinic suspicion of CF.

Methods: A total of 40 patients with borderline sweat test results (first group) and 62 patients with clinically suspected CF (second group) were investigated by next-generation sequencing for CFTR gene mutations.

Results: In the first group, 11 heterozygous (27.5\%), 1 compound heterozygous (2.5\%), and 28 homozygous (70\%) mutations were determined. In the second group, 16 heterozygous (25.8\%), 3 compound heterozygous (4.8\%), and 13 homozygous (21\%) mutations were determined. The most frequent mutations were $1148 \mathrm{~T}$ and $\triangle \mathrm{F} 508$.

Conclusion: Our research concludes that the sweat test is more important than clinical suspicion, and every patient with borderline sweat test should be immediately investigated.
\end{abstract}

Keywords: Cystic fibrosis, next-generation sequencing, sweat test, mutation

\section{INTRODUCTION}

Cystic fibrosis (CF; MIM \#219700), which was defined by Dorothy Andersen in 49 patients in New York City some 80 years ago, is currently present in the population with a 1:20-25 carrier frequency and 1:2500-3300 incidence, and it is one of the top lethal autosomal recessive diseases in the white race. There is no gender dominance in the disease. CF affects many organs and systems, causing mortality and morbidity. The most important causes of mortality are bronchiectasis, small-airway obstruction, and progressive lung injury due to infections. The most important causes of morbidity are the exocrine pancreatic insufficiency due to epithelial cell dysfunction, biliary cirrhosis, and infertility due to the absence of the vas deferens. CF is the result of mutations in the cystic fibrosis transmembrane conductance regulator (CFTR) gene, which is responsible from the anion transport, also known as the chloride transmembrane permeability channel, and in mucociliary clearance (1-5). The CFTR is a gene located on the long arm of chromosome 7, consisting of 27 exons, and containing a genomic DNA sequence of approximately $190 \mathrm{~kb}(6)$. There have been more than 2000 mutations identified in the CFTR gene; among these, missense and nonsense mutations are the most common ones, whereas the most common mutation seen alone is the Phe508del mutation (1). According to their effects on the protein function, CFTR mutations are divided into six groups (7). In Class I mutations (Gly542X, Trp1282X, and Arg553X), the protein production is not observed. In Class II mutations (Asn1303Lys and Arg560Thr), which include the most frequently observed mutation, Phe508del mutation, the degradation of proteins that are improperly folded in the endoplasmic reticulum is observed. In Class III mutations (Gly551Asp, Gly178Arg, and 
Gly551Ser), the channel regulation is impaired. Since the CFTR function is not even at a residual level in Class I, II, and III mutations, individuals with mutations in these classes show severe phenotypic effects. In Class IV mutations (Arg117His, Arg347Pro, and Arg117Cys), pathogenicity results from a reduced ion flow. In Class V (2789+5G $\rightarrow$ A, 3120+1G $\rightarrow$ A, and 3849+10kbC $\rightarrow$ T) and VI (4326delTC, GIn1412X, and 4279insA) mutations, the amount of decreased mRNA and plasma membrane instability are responsible for pathogenicity, respectively (8). In Class IV, V, and VI mutations, it is possible to say that there is a more moderate phenotypic picture because of the presence of a functional CFTR protein (1). Therefore, according to the mutation observed in patients with CF, the severity of the disease, its characteristics, and progression can be estimated.

Early identification of the disease is very important. Therefore, it has been included into the newborn screening program in our country since January 1st, 2015. Immunoreactive trypsinogen is measured by the heel stick sampling after birth. The test is repeated if the results is higher than the reference value. If the repeated test result is also found to be high, the suspected infant is referred to one of the centers for the sweat test. If the sweat test results are $>60 \mathrm{mmol} / \mathrm{L}$, the infant is directed to the CFTR gene analysis (9). If the sweat test results are $30-60 \mathrm{mmol} / \mathrm{L}$, the infant is carefully evaluated and included in a long-term followup program or investigated using a CFTR gene mutation analysis because the individual may be asymptomatic early in life but may show a CF phenotype in the following years. These individuals usually have a residual CFTR activity showing Class IV, V, or VI mutations. This situation is described as the CF metabolic syndrome in some sources (10). The frequency distribution of CF mutations varies widely across different countries and even within the same country, so various commercial kits have been developed in the light of regional data that screen 19,23,36,97, and 188 different mutations, respectively (11). The American Society of Obstetrics and Gynecology (ACOG) and the American Society of Medical Genetics (ACMG) recommend screening individuals at reproductive ages with a panel test of 23 mutations (12). The mutation detection rate of this panel test was found to be $49 \%-94 \%$ in a study conducted on European peoples (13). In the panel test made in our country that investigated 36 different mutations, this rate was determined as $75 \%$ (14). In addition to the difference of the scanned mutations, different molecular methods are also used for the mutation analysis. The most commonly used are the allele-specific oligonucleotide, reverse dot-blot hybridization, amplification refractory mutation system, oligonucleotide ligation assay, and next-generation sequencing (NGS) (5). In this study, the CFTR entire gene analysis of patients with suspected sweat test (30-60 mmol/L) or clinically diagnosed with CF in the Sanliurfa province was analyzed retrospectively, and the frequencies in our region, our country, and the world were compared in the light of the literature data.

\section{METHODS}

This retrospective study included a total of 102 individuals who were admitted to the Department of Medical Genetics of Harran University School of Medicine between October 2016 and May 2018 and who had a suspicious sweat test or were clinically initially diagnosed with CF (40 individuals with at least one suspicious test of two sweat tests at different times and 62 patients who were clinically initially diagnosed with CF). Individuals who had a family or carrier screening were not included in the study. Demographic information of the patients was collected from electronic files and noted. DNA was isolated from the 102 patients included in the study with the Magpurix Blood DNA Extraction Kit 200 from the venous blood samples taken in tubes containing $3 \mathrm{~mL}$ of ethylenediaminetetraacetic acid. After a purity and quantity analysis of the obtained DNA samples was performed by a Nanodrop SMA1000 spectrophotometer, the fluorometric assay was made using a Qubit 3.0 fluorometer device (Invitrogen, Turkey), and DNA samples were stored under suitable conditions until the DNA polymerase chain reaction (PCR) process was performed. In the PCR process, after target CF amplification (PCR1), cleaning, adapter ligation, the PCR2 steps with a barcoded primer mix sequence that has cleaning and the forward sequence of 5'AATGATACGGCGACCACCGAGATCTACACTCTTTCCCTACACGACGCTCTTCCGATCT'3 were done using the NEXTflex Cystic Fibrosis Amplicon Panel (Bioo Scientific, Austin, USA) in a thermal cycler device BIORAD T100TM Thermal Cycler (Turkey), sequencing was performed with a Miniseq (Illumina GmbH, Germany) device according to the manufacturer's protocol using the NGS method. When no pathogenic variants were detected or only one pathogenic variant was detected, the CFTR gene deletion/duplication analysis was investigated using the multiplex ligation-dependent probe amplification method. The study approval was obtained from the ethics committee of Harran University in Session 1, in January 2018.

\section{Statistical Analysis}

Data were entered into the Microsoft Excel program and analyzed with the Statistical Package for Social Sciences version 25.0 (IBM Corp.; Armonk, NY, USA) program. Data were reported as the mean \pm standard deviation using parametric tests to compare continuous variables.

\section{RESULTS}

The mean age of the participants was 5.71. The mean age was $0.68 \pm 0.24$ in the group with a suspicious sweat test, and the mean age in the group with an initial CF diagnosis was $8.96 \pm 1.47$. Of the 102 participants, 50 were female, and 52 were male. When the mutations were evaluated, in the suspicious sweat test group, of the 40 individuals, 11 were heterozygous (27.5\%), 1 was compound heterozygous (2.5\%), and 28 were homozygous (70\%) (Figure 1). When the allele frequency was evaluated in the individuals from this group, the most common observed ones were I148T (20\%), $\Delta \mathrm{F} 508$ (11.25\%), I1000Lfs * 2 (11.25\%), I1234V (8.75\%), and I807M (8.75\%) (Table 1). In the group with the initial diagnosis of CF including 62 individuals, 16 individuals were evaluated as having heterozygous (25.8\%), 3 individuals compound heterozygous (4.8\%), and 13 individual homozygous (21\%) mutations (Figure 1). No variance was observed in 30 individuals (48.4\%). When allele frequencies in this group were examined, $\Delta \mathrm{F} 508$ (7.2\%) was the most commonly observed allele (Table 2). When the individuals in the two groups were evaluated together, 27 individuals were found to have heterozygous (26.5\%), 4 had compound heterozygous (3.9\%), and 41 homozygous (40.2\%) genotypes, and in 30 individuals (29.4\%), no pathologic variant was found. When the 
two groups were evaluated together, the most common alleles found were $1148 \mathrm{~T}(9.8 \%)$ and $\Delta \mathrm{F} 508$ (8.8\%). Twenty-two different mutations were observed in 102 patients. A total of 117 mutant alleles were detected in 204 alleles (diagnostic efficacy 57.3\%). The majority of mutations were observed as missense mutations. The most commonly observed mutations were Class II and IV mutations. No pathogenicity was detected in patients studied in the deletion-duplication analysis. A written informed consent was obtained from the parents of the participants.

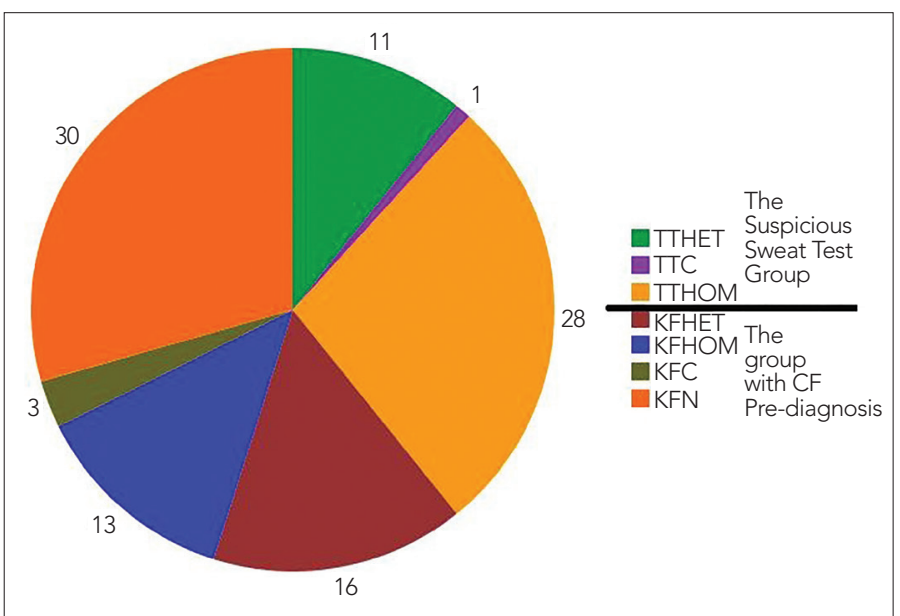

Figure 1. Graphical Representation of the Whole Gene Analysis Results of the Individuals in Both Groups

STHET: heterozygous individuals in the suspicious sweat test group; STC: compound heterozygous individuals in the suspicious sweat test group; STHOM: homozygous individuals in the suspicious sweat test group; CFHET: heterozygous individuals in the group with CF pre-diagnosis; CFHOM: homozygous individuals in the group with CF pre-diagnosis; KFC: compound heterozygous individuals in the group with CF pre-diagnosis; CFN, individuals with no mutation detected (normal) in the group with CF pre-diagnosis

Table 1. CFTR Allele frequencies in individuals with a positive sweat test

\begin{tabular}{|l|c|}
\hline Mutation & Allele Frequencies (\%) \\
\hline I148T & 20 \\
\hline$\Delta$ F508 & 11.25 \\
\hline I1000Lfs² & 11.25 \\
\hline I1234V & 8.75 \\
\hline I807M & 8.75 \\
\hline M348K & 6.25 \\
\hline S1426P & 6.25 \\
\hline E1044G & 5 \\
\hline P5L & 3.75 \\
\hline A120T & 2.5 \\
\hline A399V & 1.25 \\
\hline L997F & 1.25 \\
\hline Unidentified & 13.75 \\
\hline Total & 100 \\
\hline
\end{tabular}

\section{DISCUSSION}

In this study, a total of 102 patients with clinical initial diagnosis of CF or who had suspicious sweat test results in Sanliurfa were examined for CFTR gene mutations with a new-generation sequencing method. Expectations and predictions about CF shown as a serious problem in European countries and in studies on molecular treatment methods are that the number of adults with CF will increase by $70 \%$, and the disease will gain more importance (15). In the first decade of life, the disease presents with bronchiectasis, exocrine pancreatic insufficiency, abnormal liver function tests, and meconium ileus; after the second decade, hemoptysis, pneumothorax, progressive lung failure, diabetes, cirrhosis, portal hypertension, and osteoporosis can be observed $(1,9,15,16)$. Multidisciplinary approach and age-specific care services are important in patients with CF because of the effects of the disease on many systems and changes in this effect with age. Considering these changes, early diagnosis of the disease comes to the fore as the most important parameter. The diagnosis is usually made in the first year of life. Particularly with the inclusion of CF in a national neonatal screening program in 2015, early diagnosis rates in Turkey will increase over time. However, in some patients, the age of diagnosis can be 50 years of age. Therefore, it should

Table 2. CFTR Allele frequencies in individuals with CF Prediagnosis

\begin{tabular}{|l|c|}
\hline Mutasyon & Allele Frequencies (\%) \\
\hline$\Delta$ F508 & 7.2 \\
\hline I1000Lfs ${ }^{\star 2}$ & 5.6 \\
\hline I148T & 3.2 \\
\hline K684R & 3.2 \\
\hline I1234V & 2.5 \\
\hline I807M & 2.5 \\
\hline P1013L & 2.5 \\
\hline W1282X & 1.6 \\
\hline E1044G & 1.6 \\
\hline c.489+1G $>T$ & 1.6 \\
\hline G542X & 0.8 \\
\hline R117H & 0.8 \\
\hline M348K & 0.8 \\
\hline R553X & 0.8 \\
\hline G551D & 0.8 \\
\hline c.1585-1G>A & 0.8 \\
\hline S1426P & 0.8 \\
\hline c.2052delA & 0.8 \\
\hline R3W & 0.8 \\
\hline Unidentified & 61.3 \\
\hline Total & 100 \\
\hline
\end{tabular}


be kept in mind that patients with CF with different symptoms can be referred to any outpatient clinic $(3,9,10)$. The most important factor affecting this situation is undoubtedly the type of the mutation and the effect of mutation on the protein function.

The most common mutation in the CFTR gene in the world and in Europe is $\triangle F 508(1,13)$. The $\triangle F 508$ mutation shows a gradual decline from the northwest to the southeast in Europe and Asia (17). While in northern European countries such as Denmark this rate is close to $100 \%$, the rate is observed at $14 \%-28.5 \%$ in our country $(2,3,18)$. In a study conducted in the Adana region, which is geographically close to the province of Sanliurfa, this rate was found to be $11.9 \%$ and is close to the data of our study (3). The lowest rate of $4 \%-4.7 \%$ in Turkey was found in Izmir $(19,20)$. The ratios closest to our study were found in the studies conducted in Jordan and Bahrain $(21,22)$. The most noteworthy piece of data in our study was the observation of the I148T mutation as the most common mutation, which was not included among the first three most frequently observed mutations in the Turkish population, rather than the low mutation rate observed in $\triangle F 508$. Although this mutation was observed in less than $3 \%$ of patients with CF in many populations, it was observed to be $4 \%$ in Egypt and 6\% in Syria $(23,24)$. The fact that Sanlıurfa is neighboring Syria and hosts many Syrian migrants can be considered to be related to these data. Although there is a low probability, the I148T change may have had a "founding effect" in the region in the past. Some recent studies suggest that $1148 \mathrm{~T}$ should not be considered as a disease agent but should be considered as a phenotype modifier. In recent studies, I148T has been shown to cause atypical and mild symptoms, not classic CF symptoms (25-27). Since the relevant mutation is pathogenic in in-silico databases and is present in high rates in the suspicious sweat test group in our study, we think it may be related to mild forms of CF, even if it does not show typical CF symptoms. We think that both perspectives need to be confirmed by a prospectively designed study in more samples. This mutation has not been present since 2004 in the panel with 23 mutations proposed by the ACOG and ACMG because the rate of incidence of the relevant mutation in America is less than $0.5 \%(12,25)$. When the mutations in our study were evaluated in general, the 23 mutation panel proposed by ACOG and ACMG was able to detect $11.25 \%$ and $15.2 \%$ of the mutations in the first and second groups, respectively. This situation can be explained by the quite high diversity of the mutations in our region and the NGS method by which our study was done. In Adana, a region close to ours, 63 patients diagnosed with CF with different clinics were screened for 19 different mutations, and the diagnostic efficiency was found as $22.3 \%$. The rate of $57.3 \%$ in our study can be explained by the method used, the presence of the suspicious patient group, and the success of the clinical diagnosis.

CF clinically may be confused with immune deficiency syndromes, asthma, primary biliary atresia, primary ciliary dyskinesia, and Shwachman-Diamond syndrome. The sweat test results may be positive, particularly in bronchiectasis-related syndromes, isolated hyperchlorhidrosis, adrenal insufficiency, glycogen storage diseases, nephrogenic diabetes insipidus, and glucose-6 phosphate dehydrogenase deficiency $(28,29)$. This is an important parameter affecting the rate of diagnostic effectiveness.

\section{Limitations of the Study}

Our study is valuable as it includes two patient groups, focusing on individuals with suspected sweat test results, and is done with the NGS method. The most important limitation of the study is that it was performed retrospectively and did not examine the relationship between the mutation analysis results of the individuals and quantitative levels of the clinical and sweat test.

\section{CONCLUSION}

While the results of the analysis of the group with a suspicious sweat test supported the CF diagnosis at a rate of $72.5 \%$ (29/40), the rate was $25.8 \%(16 / 62)$ in patients with CF pre-diagnosis. We believe that this situation is important as it shows that the diagnostic value of the sweat test is more significant than clinical evaluation, as well as that the individuals who are suspicious for sweat test should be investigated immediately. As a result, 102 individuals with suspicious sweat test results and a clinical prediagnosis of CF were retrospectively analyzed using the NGS method and were discussed in the light of current information, and regional and national data.

Ethics Committee: Ethics committee approval was received for this study from the Ethics Committee of Harran University School of Medicine.

Informed Consent: Written informed consent was obtained from the parents of the patients who participated in this study.

Peer-review: Externally peer-reviewed.

Conflict of Interest: The author has no conflict of interest to declare.

Financial Disclosure: The author declared that this study has received no financial support.

\section{REFERENCES}

1. Elborn JS. Cystic fibrosis. Lancet 2016; 388: 2519-31. [CrossRef]

2. Tug E, Tug T. Kistik Fibrozis ve Moleküler-Genetik Yaklasımlar. Toraks Derg 2003; 4: 198-204.

3. Öztürk ÖG, Kibar F, Karaçor EDZ, Çetiner S, Şahin G, Yaman A. Adana Illinde CFTR Gen Mutasyonlarının Değerlendirilmesi. Cukurova Med J 2014; 38: 202-8.

4. Oskoui M, Gazzellone MJ, Thiruvahindrapuram B, Zarrei M, Andersen J, Wei J, et al. Clinically relevant copy number variations detected in cerebral palsy. Nat Commun 2015; 6: 7949. [CrossRef]

5. Richards CS, Bradley LA, Amos J, Allitto B, Grody WW, Maddalena A, et al. Standards and Guidelines for CFTR Mutation Testing. Genet Med 2002; 4: 379-91. [CrossRef]

6. Zielenski J, Rozmahel R, Bozon D, Kerem BS, Grzelczak Z, Riordan JR, et al. Genomic DNA sequence of the cystic fibrosis transmembrane conductance regulator (CFTR) gene. Genomics 1991; 10: 214-28. [CrossRef]

7. Wilschanski M, Zielenski J, Markiewicz D, Tsui LC, Corey M, Levison $\mathrm{H}$, et al. Correlation of sweat chloride concentration with classes of the cystic fibrosis transmembrane conductance regulator gene mutations. J Pediatr 1995; 127: 705-10. [CrossRef]

8. Boyle MP, De Boeck K. A new era in the treatment of cystic fibrosis: correction of the underlying CFTR defect. Lancet Respir Med 2013; 1: 158-63. [CrossRef]

9. Üstü Y, Uğurlu M. Ulusal Erken Tanı ve Tarama Programı: Kistik Fibrozis National Early Diagnosis and Screening Program: Cystic Fibrosis. Ankara Med J 2016; 16: 239-41. [CrossRef]

10. McCloskey M, Redmond AOB, Hill A, Elborn JS. Clinical Features Associated with a Delayed Diagnosis of Cystic Fibrosis. Respiration 2000; 67: 402-7. [CrossRef] 
11. Lucarelli M, Porcaro L, Biffignandi A, Costantino L, Giannone V, Alberti L, et al. A New Targeted CFTR Mutation Panel Based on Next-Generation Sequencing Technology. J Mol Diagn 2017; 19: 788-800. [CrossRef]

12. Loukas YL, Thodi G, Molou E, Georgiou V, Dotsikas Y, Schulpis KH. Clinical diagnostic Next-Generation sequencing: The case of CFTR carrier screening. Scand J Clin Lab Invest 2015; 75: 374-81. [CrossRef]

13. Lao O, Andrés AM, Mateu E, Bertranpetit J, Calafell F. Spatial patterns of cystic fibrosis mutation spectra in European populations. Eur J Hum Genet 2003; 11: 385-94. [CrossRef]

14. Kilinç MO, Ninis VN, Dağli E, Demirkol M, Ozkinay F, Arikan Z, et al. Highest heterogeneity for cystic fibrosis: 36 mutations account for 75\% of all CF chromosomes in Turkish patients. Am J Med Genet 2002; 113: 250-7. [CrossRef]

15. Burgel PR, Bellis G, Olesen HV, Viviani L, Zolin A, Blasi F, et al. Future trends in cystic fibrosis demography in 34 European countries. Eur Respir J 2015; 46: 133-41. [CrossRef]

16. Gokdemir Y, Erdem E, Akpınar IN, Ersu R, Karadag B KF. Orta ve ağır akciğer tutulumu olan kistik fibrozlu hastalarda ölüme etki eden diğer risk etmenleri. Turk J Pediatr 2012; 47: 267-71. [CrossRef]

17. De Boeck K, Zolin A, Cuppens H, Olesen HV, Viviani L. The relative frequency of CFTR mutation classes in European patients with cystic fibrosis. J Cyst Fibros 2014; 13: 403-9. [CrossRef]

18. Bonyadi M, Omrani O, Rafeey M, Bilan N. Spectrum of CFTR Gene Mutations in Iranian Azeri Turkish Patients with Cystic Fibrosis. Genet Test Mol Biomarkers 2011; 15: 89-92. [CrossRef]

19. Kosova B, Eroglu Z, Yılmaz B, Gündüz C, Özel R, Sayın E, et al. $\triangle F 508, \triangle 1507$ ve $F 508 C$ kistik fibroz mutasyonlarının gerçek-zamanlı multipleks PCR ile hızlı analizleri. Ege Tıp Derg 2008; 47: 103-9.
20. Ülgenalp A. Strip Assay Metodu Kullanılarak "Cystic Fibrosis Transmembrane Conductance Regulator (CFTR)" Geni Mutasyonlarının Analizi, Dokuz Eylül Üniversitesi Tıp Fakültesi Derg 2009; 23: 47-51.

21. Rawashdeh $M$, Manal $H$. Cystic fibrosis in Arabs: a prototype from Jordan. Ann Trop Paediatr 2000; 20: 283-6. [CrossRef]

22. Eskandarani HA. Cystic fibrosis transmembrane regulator gene mutations in Bahrain. J Trop Pediatr 2002; 48: 348-50. [CrossRef]

23. Shahin WA, Mehaney DA, El-Falaki MM. Mutation spectrum of Egyptian children with cystic fibrosis. Springerplus 2016; 5: 686. [CrossRef]

24. Jarjour RA, Al-Berrawi S, Ammar S, Majdalawi R. Spectrum of cystic fibrosis mutations in Syrian patients. Minerva Pediatr 2018; 70: 159-64.

25. Watson MS, Cutting GR, Desnick RJ, Driscoll DA, Klinger K, Mennuti $M$, et al. Cystic fibrosis population carrier screening: 2004 revision of American College of Medical Genetics mutation panel. Genet Med 2004; 6: 387-91. [CrossRef]

26. Brennan M-L, Schrijver I. A Review of Associated Phenotypes, Use of Molecular Diagnostic Approaches, Genetic Characteristics, Progress, and Dilemmas. J Mol Diagn 2016; 18: 3-14. [CrossRef]

27. Monaghan KG, Highsmith WE, Amos J, Pratt VM, Roa B, Friez M, et al. Genotype-phenotype correlation and frequency of the 3199del6 cystic fibrosis mutation among I148T carriers: Results from a collaborative study. Genet Med 2004; 6: 421-5. [CrossRef]

28. Feldshtein M, Elkrinawi S, Yerushalmi B, Marcus B, Vullo D, Romi H, et al. Hyperchlorhidrosis Caused by Homozygous Mutation in CA12, Encoding Carbonic Anhydrase XII. Am J Hum Genet 2010; 87: 713-20. [CrossRef]

29. Sheridan MB, Fong P, Groman JD, Conrad C, Flume P, Diaz R, et al. Mutations in the beta-subunit of the epithelial $\mathrm{Na}+$ channel in patients with a cystic fibrosis-like syndrome. Hum Mol Genet 2005; 14: 3493-8. [CrossRef] 